\title{
EOQ inventory model for perishable products under uncertainty
}

\author{
R. Patriarca ${ }^{1}$ - G. Di Gravio ${ }^{1} \cdot$ F. Costantino ${ }^{1} \cdot$ M. Tronci $^{1}$
}

Received: 29 May 2020 / Accepted: 22 September 2020 / Published online: 12 October 2020

(c) The Author(s) 2020

\begin{abstract}
Perishable products require accurate inventory control models as their effect on operations management can be critical. This assumption is particularly relevant in highly uncertain and dynamic markets, as for the ones generated by the pandemic era. This paper presents an inventory control model for perishable items with a demand rate variable over time, and dependent on the inventory rate. The model also considers the potential for backlogging and lost sales. Imperfect product quality is included, and deterioration is modelled as a time-dependent variable. The framework envisages the possibility to define variables affected by uncertainty in terms of probability distribution functions, which are then jointly managed via a Monte Carlo simulation. This paper is intended to provide an analytical formulation to deal with uncertainty and time-dependent inventory functions to be used for a variety of perishable products. The formulation is designed to support decision-making for the identification of the optimal order quantity. A numerical example exemplifies the outcomes of the paper and provides a cost-based sensitivity analysis to understand the role of main parameters.
\end{abstract}

Keywords Inventory management $\cdot$ Deteriorated products $\cdot$ Defective products $\cdot$ Disposal cost $\cdot$ COVID19

$\begin{array}{ll}\text { List of symbols } \\ a\left[\frac{\text { unit }}{t}\right] & \text { Demand rate in } D(t=0)(a>0) \\ b\left[\frac{\text { unit }}{t^{2}}\right] & \text { Demand rate coefficient }(b \neq 0) \\ b_{c}\left[\frac{€}{\text { unit*t }}\right] & \text { Unit backorder cost } \\ c\left[\frac{\text { unit }}{t^{3}}\right] & \text { Demand rate coefficient }(c \neq 0) \\ d\left[\frac{€}{\text { unit }}\right] & \text { \{lrm unit }\} \text { deteriorating cost } \\ g\left[\frac{€}{\text { unit }}\right] & \text { Constant coefficient of the holding cost } \\ h\left[\frac{€}{\text { unit*t }}\right] & \text { Variable coefficient of the holding cost } \\ l_{s}\left[\frac{€}{\text { unit }}\right] & \text { Unit lost sale cost } \\ s\left[\frac{€}{\text { unit }}\right] & \text { Unit screening cost } \\ t_{1}[t] & \text { Screening process starting time } \\ t_{2}[t] & \text { Stock-out starting time }\end{array}$

R. Patriarca

riccardo.patriarca@uniroma1.it

1 Department of Mechanical and Aerospace Engineering, Sapienza University of Rome, Via Eudossiana, 18, 00184 Rome, Italy

\begin{tabular}{|c|c|}
\hline$\alpha$ & Percentage of defective products \\
\hline$\theta\left[\frac{\text { unit }}{t}\right]$ & Deterioration rate \\
\hline$\lambda\left[\frac{\text { unit }}{t}\right.$ & Screening rate \\
\hline$\mu[t]$ & Deterioration process starting time \\
\hline$\varphi \frac{1}{t}$ & Backlogging parameter $(\varphi>0)$ \\
\hline$B_{r}(t)$ & Backlogging rate \\
\hline$D(t)\left[\frac{\text { unit }}{t}\right]$ & Demand rate \\
\hline$D_{b}\left[\frac{\text { unit }}{t}\right]$ & Demand rate when inventory is null \\
\hline$H(t)\left[\frac{€}{\text { unit }}\right]$ & Holding cost function \\
\hline$I_{0}[$ unit $]$ & Maximum inventory level \\
\hline$I_{l}(t)[$ unit $]$ & Inventory level in the time interval $\left[0, \mathrm{t}_{1}\right]$ \\
\hline$I_{1}^{\prime}(t)[$ unit $]$ & Inventory level in the time interval $\left[\mathrm{t}_{1}, \mu\right]$ \\
\hline$I_{2}(t)[$ unit $]$ & Inventory level in the time interval $\left[\mu, t_{2}\right]$ \\
\hline$I_{3}(t)[$ unit $]$ & Inventory level in the time interval $\left[\mathrm{t}_{2}, \mathrm{~T}\right]$ \\
\hline$I_{d}[$ unit $]$ & $\begin{array}{l}\text { Inventory level in } \mathrm{t}_{1} \text {, considering defective } \\
\text { products }\end{array}$ \\
\hline$I_{s}[$ unit $]$ & $\begin{array}{l}\text { Inventory level in } t_{1} \text {, without defective } \\
\text { products }\end{array}$ \\
\hline$I_{\mu}[$ unit $]$ & Inventory level in $\mu$ \\
\hline$Q[$ unit $]$ & Ordered quantity \\
\hline$Q_{b}[$ unit $]$ & Maximum backorder quantity \\
\hline$T[t]$ & Inventory cycle length \\
\hline
\end{tabular}




\section{Introduction}

The economic order quantity (EOQ) is an inventory control model largely accepted in industrial operations management, since its introduction in the earliest decades of the twentieth century [1]. However, the original model presents several unrealistic assumptions that motivated scholars to study the EOQ under real-life scenarios [2]. One of the more investigated area refers to products that suffer of a short lifecycle. This vast literature becomes particularly relevant in current days for the identification of the control models to be adopted for sustainable inventory and production management. Besides traditional food and beverage products, more critical items refer indeed to medical supplies such as surgical masks, reagents, swabs, pads that in the pandemic era require even more accurate ordering and replenishment strategies.

From a production management perspective, such products are currently critical, due to the large size of demand required by societal needs and subjected to public purchasing with urgent timing. The batch size becomes a crucial variable considering the difficulties arising in product transferring between suppliers and customers. Products may also suffer from possible damages during deliveries, reducing their quality level. The highly dynamic current market also pushes competition over quality, jeopardizing products' integrity, as well as facilitating products' deterioration. Furthermore, since in real settings all these features are largely affected by uncertainty, deterministic inventory models become no more effective for the minimization of respective management costs.

An opportunity emerges here to further investigate and refine an EOQ model in light of the features required to support a sustainable production management for products that are strategic during a pandemic. It thus becomes necessary to ensure that operations rely on optimization of parameters referred to reduced quality of products over time, and to the deterioration effects on customers' purchasing interest. In addition, deterioration may also yield waste, which has to be disposed, generating not-negligible disposal cost.

On these assumptions, this paper contributes to the field of production engineering research by proposing a new model that can take into account costs related to perishable products, along with the uncertainty of demand and quality level, and the associated effect on customers, i.e. backordering or lost sales. Even though this document presents an integrated formulation for modelling the features of pandemic related items, the model has been built to provide an analytic formulation easily extensible to a large set of perishable products (e.g. pharmaceutical, food and beverages).

The remainder of the paper is organized as follows. Section 2 provides a literature review on more relevant EOQ models for perishable products. Section 3 details the proposed integrated analytical model, which is then exploited via a numerical Monte Carlo simulation in Sect. 4. Finally, the conclusions summarize the outcome of this work and the potential for future research.

\section{Literature review}

Products can lose their value during storage due to: (1) obsolescence, i.e. losing value over time due to technological changes or substitutes entering the market; (2) deterioration, i.e. the change or decay of the physical characteristics of a product which results in a reduction in the usefulness. Products affected by deterioration can be classified as perishable, with a known lifetime and expiry date, and decaying, with unknown lifetime. The ones characterized by high deterioration rate can generate stock-out, lost sales and disposal costs [3].

In EOQ models for perishable products, each batch presents a constant or variable rate of deterioration that can move compliant products to defective, even after their receipt in the factory. In recent years, an instantaneous deterioration at a constant rate has been proposed with a demand linearly increasing in time, assuming full recovery of backorder after replenishment [4]. Karthikeyan and Santhi [5] consider the demand as a cubic function over time, for which stock-out is not allowed but products have a salvage value. Khurana and Chaudhary [6] follow a demand depending on both the level of available stock and price, and then develop two models with a different backlogging rate, i.e. constant or depending on the waiting time until the arrival of the next batch. Mahapatra [7] study a model for high reliability products: buyers are inclined to acquire high-quality products to reduce maintenance costs and the possibility of failure, stock-out is partially managed in backorder. Kumar [8] examines the effect of a time-dependent linear demand in case of positive stock level, and a constant demand during stock-out. Tripathi [9] develops a model for seasonal food products with quadratic demand over time, and possible stock-out with no lost sale. Shaikh [10] proposes a model with temporary discount on the purchase unit cost, where the demand function depends on the price and the level of available stock, while during stock-out the demand depends only on the price of the product.

A further specialization for perishable products provides a constant rate with non-instantaneous deterioration, starting after a certain amount of time [11]. In particular, Tat et al. [12] develop a model for a two-tier supply chain, allowing stock-out. Palanivel and Uthayakumar [13] consider the demand function dependent on price and 
advertising, assessing the effect of inflation and the time value of money.

In reality, a constant rate of deterioration rarely occurs as most products deteriorate more as time passes. Mishra [14] present the demand as a linear function over time when the stock level is positive, becoming constant during stockout, and backlogging rate inversely proportional to the lead time of the next replenishment. With the same assumptions, Singh [15] develop a model with a time-dependent deterioration rate and no stock-out allowed, where the demand rate changes over time, i.e. constant over time before deterioration, and linear in time after deterioration starts.

Other examples of a variable rate consider the adoption of Weibull distribution. For instantaneous deterioration, a twoparameter Weibull distribution is proposed by: Rajoria et al. [16] (with both time-dependent demand and backlogging rate, considering inflation), Sharma et al. [17] (price and expiry-date dependent demand and two backlogging rates, constant or variable) and Pervin et al. [18] (linear demand over time and partial backorder). A two-parameter Weibull distribution can be used if the deterioration rate is decreasing and the initial value is very high or if it is increasing with an initial value approximately null. Otherwise, (e.g.) when the deterioration starts after a certain period, a three-parameter Weibull distribution is required: Sanni and Chukwu [19] develop a model with time-dependent quadratic demand and partial backorder; Singh et al. [20] develop a model for a new seasonal product with time-dependent ramp demand, possible stock-out and full recovery. Finally, Palanivel and Uthayakumar [21] present a model where the demand is a function of price, advertising, and inflation, admitting stockouts, and partial backlogging with a rate depending on the lead time until the arrival of the next batch. The deterioration starts only after a certain period with a rate represented by three continuous probability distributions: uniform, triangular, and beta.

From the analysis of this literature, it emerges the need to develop a model which is able to represent the features of a complex scenario such as the one present during a pandemic, via an analytic formulation which is also subjected to uncertainty. On these bases, this paper presents an integrated EOQ inventory control model for perishable products, subject to variable defectiveness checked during quality control and time-dependent deterioration, which can cause both backorder and lost sale. The proposed paper indeed integrates different analytical formulations discussed individually in previous research and adopts Monte Carlo simulation to solve the resulting optimization problem. In addition to the integrated analytical nature of this work (whose detail choices have been discussed in detail in Sect. 3), the contribution proposed here is intended to support decision-making with a clear representation of uncertainty effects.

\section{Analytical model}

The analytical formulation models an economic order quantity problem for a single perishable item. The deterioration of the products determines the likely possibility of generating an anticipated stock-out situation [22], which is considered in a partial backlogging scenario. The deterioration rate starts after a specific known time moment $\mu$ and is a random variable [13]. No substitution or repair of deteriorated products is allowed during the re-ordering period. In practical terms, the total costs referred to this situation are represented by a combination of holding cost (cost due to the materials stocked in the warehouse), screening cost (cost to be paid for checking the quality of products), disposal costs (cots required to dispose the products that do not satisfy the quality level after the initial screening, or when the deterioration starts); the shortage cost (cost to be paid when the demand is not matching the remaining inventory), and the lost sale costs (cost paid in case there is left in the inventory at the moment of re-ordering). Figure 1 summarizes conceptually the different cost components, as a basis for the subsequent mathematical formulation.

Additional specific features of the model can be summarized as follows:

- Replenishment occurs instantaneously

- The demand is stock-dependent: a quadratic function in standard situations [19], and constant influenced by $B_{r}(t)$ during the stock-out period [14].

$D(t)=\left\{\begin{array}{c}a+b t+c t^{2} 0 \leq t \leq t_{2} \\ D_{b} B_{r}(t) t_{2} \leq t \leq T\end{array}\right.$

- DETERIORATION. The products can be sold until T, which corresponds to the expiry date of the product in question, assumed to be equal to the inventory ordering cycle. Products left in stock after T constitute lost sales, since they do not respect the requirements of the customer.

- BACKLOGGING. The backlogging rate $B_{r}(t)$, i.e. the portion of demand to be satisfied in backorder, is variable and is dependent on the length of the waiting time for the next replenishment: a longer backlogging rate would imply a smaller portion of customers would accept backlogging at time $t$. This situation is described in case of negative inventory, as follows [15]:

$B_{r}(t)=\frac{1}{1+\varphi(T-t)} t_{2} \leq t \leq T$

where $(T-t)$ is the remaining time before next replenishment, and $\varphi>0$ is a factor inversely representing the backorder rate imposed by the company: $\varphi=0$ implies a full backorder management $B_{r}(t)=1$, with progressively lower backlogging rates for larger values of $\varphi$. 


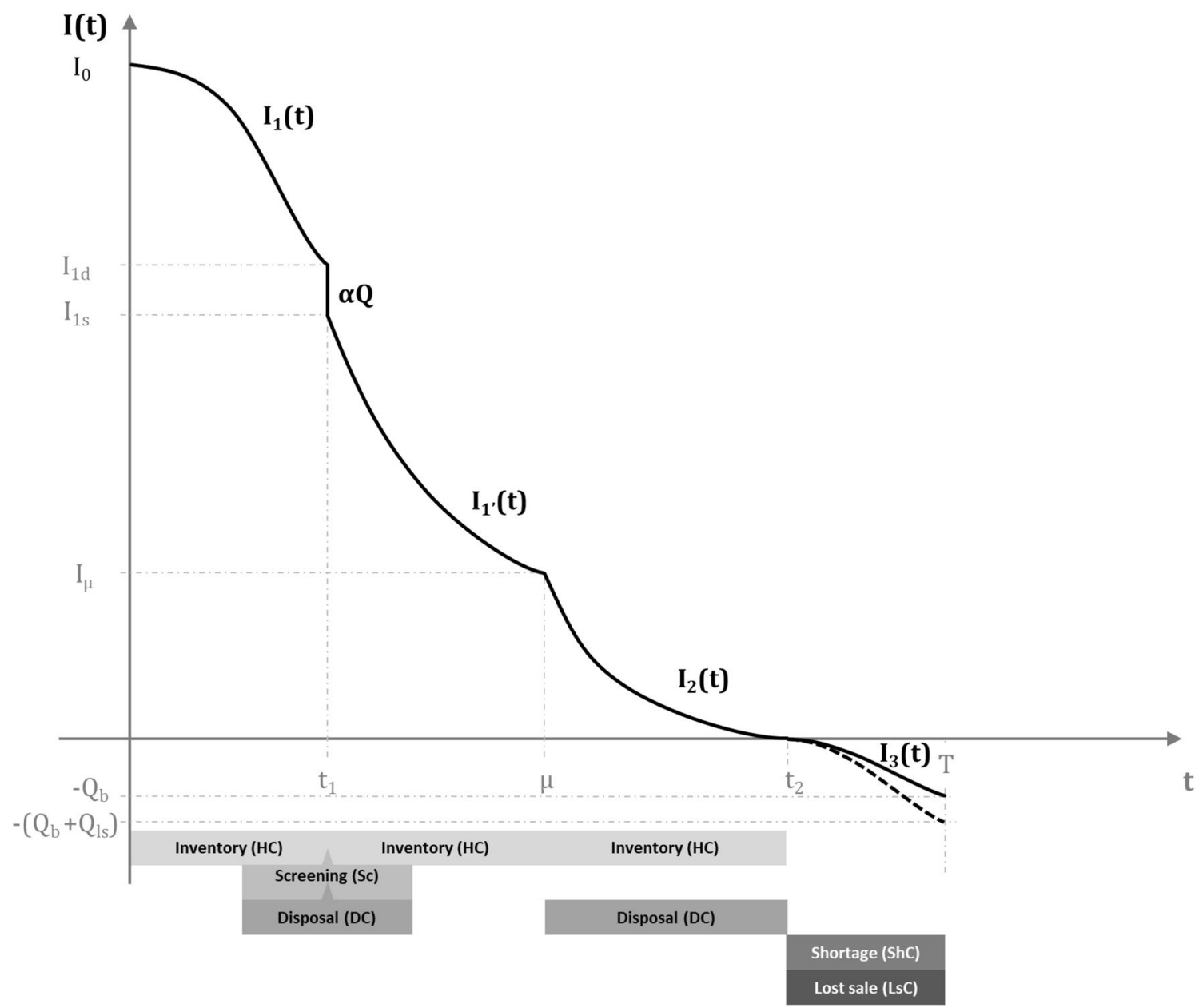

Fig. 1 Conceptual overview of the stock level in a period T

- DEFECTIVENESS. Every order includes a percentage of defective products $\alpha$, which is a random variable whose probability density function $f(\alpha)$ is uniform and known [23]. Screening is conducted in the interval $\left[0, t_{1}\right]$ with a screening frequency $\lambda$. The screening process is assumed to be perfect: no mis-classified products are possible. All defective units are removed contemporarily from the inventory at the end of the screening process, i.e. $t_{1}$. The screening rate is sufficiently large to ensure that a number of products larger than the demand is screened in $\left[0, t_{1}\right]$. This assumption is acceptable since the screening process takes only little time, especially considering modern automated technologies for screening. The defective items are independent of deterioration $\left(t_{1}<\mu\right)$. A constraint on $\alpha$ is needed to avoid stockout during the screening process:

$$
(1-\alpha) Q>D(t) t_{1} \rightarrow \alpha \leq 1-\frac{D(t)}{\lambda}, t_{1}=\frac{Q}{\lambda}
$$

- HOLDING. The holding cost per unit is proportional to both the storage time and consists of two compo- nents: a constant part $(g)$ and another part linearly increasing with the storage time $(h)$. The holding cost function is $H(t)=(g+h t)$. This assumption motivates the potential benefits of larger holding cost to compensate the deterioration process increasing over time [10].

The stock level in $t=0$ corresponds to the maximum level of inventory $I(t=0)=I_{0}$. In the time interval $[0, \mu]$ the stock level decreases following the demand $D(t)$ :

$\frac{\partial I_{1}(t)}{\partial t}=-D(t), 0 \leq t \leq \mu$

where imposing $I_{1}(0)=I_{0}$, and considering and $t_{1}$ as a function of the screening rate $\lambda, t_{1}=\frac{Q}{\lambda}$ :

$I_{1}(t)=I_{0}-\left(a t+\frac{b}{2} t^{2}+\frac{c}{3} t^{3}\right), 0 \leq t \leq t_{1}$

The inventory level including defective products is $I_{1 d}\left(t_{1}\right)$ : 
$I_{1 d}\left(t_{1}\right)=I_{0}-\left(a t_{1}+\frac{b}{2} t_{1}^{2}+\frac{c}{3} t_{1}^{3}\right)$

Since the amount of defective items $t_{1}$ is equal to $\alpha Q$ [23], the actual level of usable products is:

$I_{1 s}\left(t_{1}\right)=I_{1 d}\left(t_{1}\right)-\alpha Q$

Consequently, the stock level in $\left[t_{1}, \mu\right]$ can be modelled as:

$I_{1^{\prime}}(t)=I_{0}-\left(a t+\frac{b}{2} t^{2}+\frac{c}{3} t^{3}\right)-\alpha Q, t_{1} \leq t \leq \mu$

where $I_{1^{\prime}}(\mu)=I_{\mu}$.

Since deterioration starts at $\mu$, the inventory level in $\left[\mu, t_{2}\right]$ is:

$\frac{\partial I_{2}(t)}{\partial t}+\theta I_{2}(t)=-D(t), \mu \leq t \leq t_{2}$ $\frac{\partial I_{3}(t)}{\partial t}=-D_{b} B_{r}(t), t_{2} \leq t \leq T$

where, the condition $I_{3}\left(t_{2}\right)=0$ is needed to ensure the backorder condition, starting after $t_{2}$ :

$\frac{\partial I_{3}(t)}{\partial t}=-\frac{D_{b}}{1+\varphi(T-t)}, t_{2} \leq t \leq T$

And consequently, the value of $I_{3}(t)[15]$ :

$I_{3}(t)=\frac{D_{b}}{\varphi}\left[\ln (1+\varphi(T-t))-\ln \left(1+\varphi\left(T-t_{2}\right)\right)\right], t_{2} \leq t \leq T$

Here, $Q_{b}$ is obtained for $t=T$, i.e. the maximum amount of demand backlogged per cycle:

$Q_{b}=-I_{3}(T)=\frac{D_{b}}{\varphi} \ln \left[1+\varphi\left(T-t_{2}\right)\right]$

Hence $Q$ :

$Q=I_{0}+Q_{b}==\frac{\frac{1}{\theta}\left\{\left[\left(a+b t_{2}+c t_{2}^{2}\right)-\left(\frac{b+2 c t_{2}}{\theta}\right)+\frac{2 c}{\theta^{2}}\right] e^{\theta\left(t_{2}-\mu\right)}-\left[\left(a+b \mu+c \mu^{2}\right)-\left(\frac{b+2 c \mu}{\theta}\right)+\frac{2 c}{\theta^{2}}\right]\right\}}{(1-\alpha)}$

$$
+\frac{\left(a \mu+\frac{b}{2} \mu^{2}+\frac{c}{3} \mu^{3}\right)+\alpha Q_{b}}{(1-\alpha)}+\frac{D_{b}}{\varphi} \ln \left[1+\varphi\left(T-t_{2}\right)\right]
$$

This differential equation can be solved imposing $I_{2}(\mu)=I_{\mu}$ and $I_{2}\left(t_{2}\right)=0[9]$ :

Then the respective inventory management costs can be calculated, as for the following formulas:

$I_{2}(t)=\frac{1}{\theta}\left\{\left[\left(a+b t_{2}+c t_{2}^{2}\right)-\left(\frac{b+2 c t_{2}}{\theta}\right)+\frac{2 c}{\theta^{2}}\right] e^{\theta\left(t_{2}-t\right)}-\left[\left(a+b t+c t^{2}\right)-\left(\frac{b+2 c t}{\theta}\right)+\frac{2 c}{\theta^{2}}\right]\right\}$

Considering $I_{1^{\prime}}(\mu)=I_{2}(\mu)$ :

$I_{0}-\left(a \mu+\frac{b}{2} \mu^{2}+\frac{c}{3} \mu^{3}\right)$

$-\alpha Q=\frac{1}{\theta}\left\{\left[\left(a+b t_{2}+c t_{2}^{2}\right)-\left(\frac{b+2 c t_{2}}{\theta}\right)+\frac{2 c}{\theta^{2}}\right] e^{\theta\left(t_{2}-\mu\right)}-\left[\left(a+b \mu+c \mu^{2}\right)-\left(\frac{b+2 c \mu}{\theta}\right)+\frac{2 c}{\theta^{2}}\right]\right\}$

where, after simple mathematical manipulations and con-

sidering $Q=I_{0}+Q_{b}$ :

$I_{0}=\frac{\frac{1}{\theta}\left\{\begin{array}{c}{\left[\left(a+b t_{2}+c t_{2}^{2}\right)-\left(\frac{b+2 c t_{2}}{\theta}\right)+\frac{2 c}{\theta^{2}}\right] e^{\theta\left(t_{2}-\mu\right)}} \\ -\left[\left(a+b \mu+c \mu^{2}\right)-\left(\frac{b+2 c \mu}{\theta}\right)+\frac{2 c}{\theta^{2}}\right]\end{array}\right\}+\left(a \mu+\frac{b}{2} \mu^{2}+\frac{c}{3} \mu^{3}\right)+\alpha Q_{b}}{(1-\alpha)}$ [14]:

After $t_{2}$, a partial backorder phenomenon is activating

- Screening Cost: 
Table 1 Values of adopted variables and parameters

\begin{tabular}{ll}
\hline Variable & Base scenario \\
\hline$a$ & Normal $(100,10)$ \\
$b$ & Normal $(50,5)$ \\
$b_{c}$ & 0.2 \\
$c$ & Normal $(10,1)$ \\
$d$ & 0.03 \\
$g$ & 0.003 \\
$h$ & 0.001 \\
$l_{s}$ & 0.07 \\
$s$ & 0.001 \\
$\alpha$ & Uniform $(0,0.1)$ \\
$\theta$ & 0.2 \\
$\lambda$ & Uniform $(5000,6000)$ \\
$\mu$ & 2 \\
$\varphi$ & 0.1 \\
$D_{b}$ & Triangular $(60,60,80)$ \\
$T$ & 6 \\
\hline
\end{tabular}

The distributions' parameters are synthetically described as follows: normal (mean, std. dev), triangular (min, mode, max), uniform (min, $\max )$.

$$
S c C=s Q
$$

- Holding Cost:

$$
H C=\int_{0}^{t_{1}} H(t) I_{1}(t) d t+\int_{t_{1}}^{\mu} H(t) I_{1^{\prime}}(t) d t+\int_{\mu}^{t_{2}} H(t) I_{2}(t) d t=H C_{1}+H C_{2}+H C_{3}
$$

Full details on analytical characteristics of $H C_{1}, H C_{2}$, and $H C_{3}$ are presented in the Appendix.

- Disposal Cost:

$D C=d\left(Q_{d}+\alpha Q\right)$

where $Q_{d}$ represents the amount of deteriorated products in $\left[\mu, t_{2}\right]$ :
Finally, the total cost is the sum of the previous elements:

$T C=S c C+H C+D C+S h C+L s C$

\section{Numerical example}

The complicated structure of the proposed formulation does not allow an efficient analytical closed-form solution, especially when considering the probabilistic nature of the mentioned variables. As such, the problem has been solved via a Monte Carlo simulation model, which ensures a relatively simple, flexible, and computationally efficient analysis. Each Monte Carlo simulation consisted of 5000 iterations [24], relying on Mersenne twister, an efficient pseudo-random numbers generating algorithm.

\subsection{Base scenario}

The model has been then validated with the data presented in Table 1. Besides a base scenario which summarizes the values representative of plausible settings, a sensitivity analysis has been performed to study the impact of main variables on the order quantity and respective total cost. The numerical values assigned in the base scenario have been based on

$Q_{d}=I_{\mu}-\int_{\mu}^{t_{2}} D(t) d t=I_{0}(1-\alpha)-\left(a \mu+\frac{b}{2} \mu^{2}+\frac{c}{3} \mu^{3}\right)-\alpha Q_{b}-t_{2}\left(a+\frac{b}{2} t_{2}+\frac{c}{3} t_{2}^{2}\right)+\mu\left(a+\frac{b}{2} \mu+\frac{c}{3} \mu^{2}\right)$

- Shortage cost [14]:

$\operatorname{ShC}=b_{c}\left[-\int_{t_{2}}^{T} I_{3}(t) d t\right]=-\frac{b_{c} D_{b}}{\varphi} \int_{t_{2}}^{T}\left[\ln (1+\varphi(T-t))-\ln \left(1+\varphi\left(T-t_{2}\right)\right)\right]=b_{c} D_{b}\left[\frac{T-t_{2}}{\varphi}-\frac{1}{\varphi^{2}} \ln \left(1+\varphi\left(T-t_{2}\right)\right]\right.$

- Lost sales cost [14]:

$L s C=l Q_{l s}=l \int_{t_{2}}^{T}\left[D_{b}\left(1-\frac{1}{1+\varphi(T-t)}\right)\right] d t=l D_{b}\left[T-t_{2}-\frac{1}{\varphi} \ln \left(1+\varphi\left(T-t_{2}\right)\right)\right]$ 


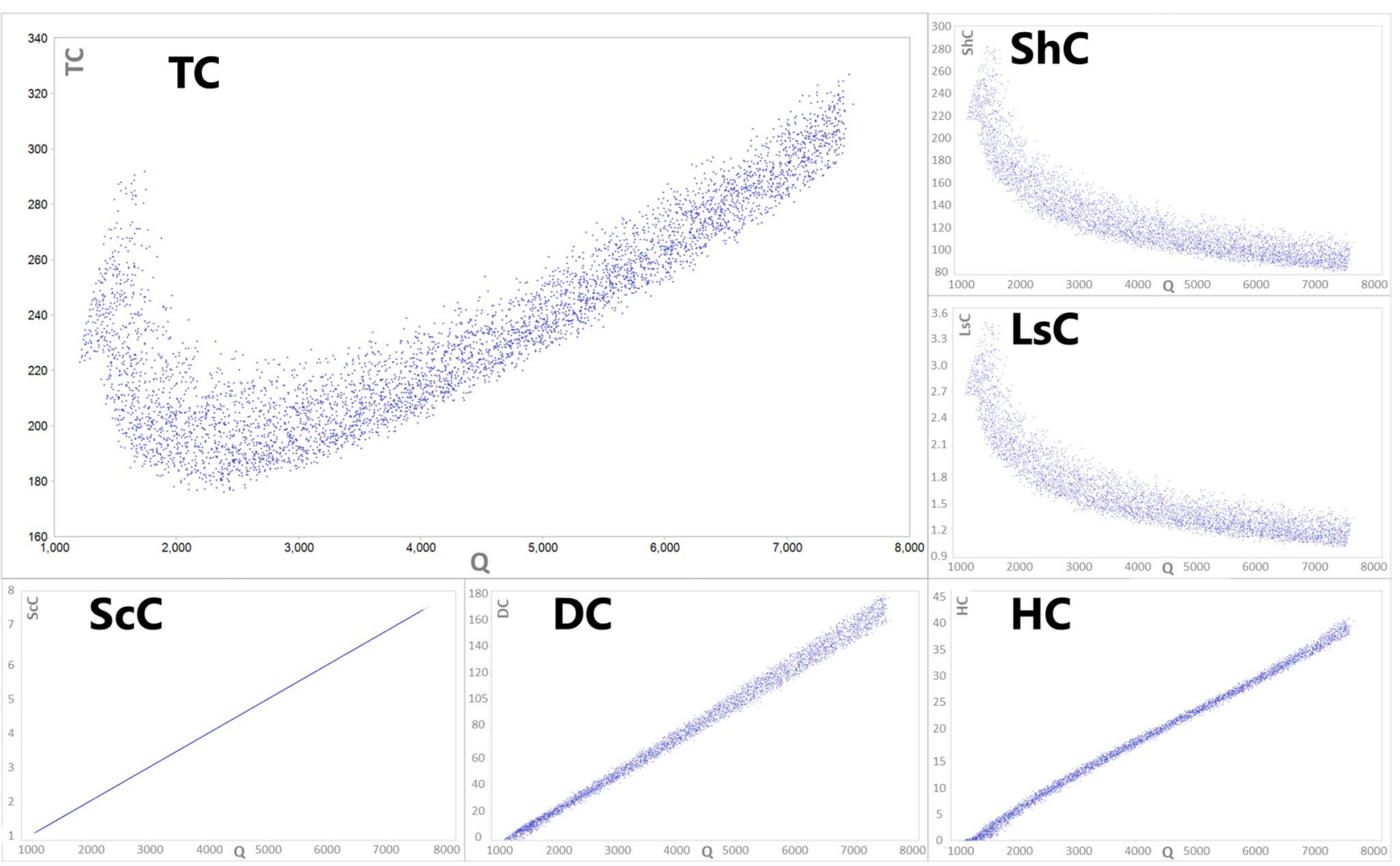

Fig. 2 Cost vs quantity functions in the base scenario

validity and robustness of the results with different input values.

From the analysis of results presented in Fig. 2, it clearly appears the major contribution to the total cost (TC) played by the shortage cots (ShC) and the disposal cost (DC), which shows a similar pattern of the holding cost (HC). This probabilistic analysis confirms the trade-off to be set to ensure an economical order strategy.

This analysis can be used as a support for decisionmaking under uncertainty, as shown in Fig. 3. Besides the inherent uncertainty on the demand value, there could be randomness in any of the proposed variable. Therefore, a certain threshold on the total cost (vertical axis) can be set to understand the feasibility of an imposed budget constraint. The decision-maker can thus establish a certain range of $\mathrm{Q}$ to assess the effect on total cost (or of course, on any other cost).

For example, within the range of Q $(1500,3500)$, the total cost will exceed the budget constraint $(\mathrm{TC}=220)$ only for about $6 \%$. A larger or shorter range can be proposed, depending on exogenous variables (e.g. supplier's constraint on ordering quantity).

\subsection{Sensitivity analysis}

Three sensitivity analyses have been performed to study the impact of the defect rate $\alpha$ ), deterioration $(\theta)$, and the backlogging parameter $(\varphi)$. Results show consistency with potential real scenarios, as detailed in the following figures (see Figs. 4, 5, 6).

\subsubsection{Defective products ratio}

The sensitivity analysis on the defective product ratio shows that there is no significant contribution to the total cost, while deviations can be ascribed to the random nature of the other variables: $\alpha$ has been set ranging from 0 (no defect) to 0.10 (10 percentage of defective products during screening), as shown in Fig. 4.

\subsubsection{Deterioration rate}

About the deterioration rate, as it increases, there is a significant increase in the required lot size $(\mathrm{Q})$, and associated 


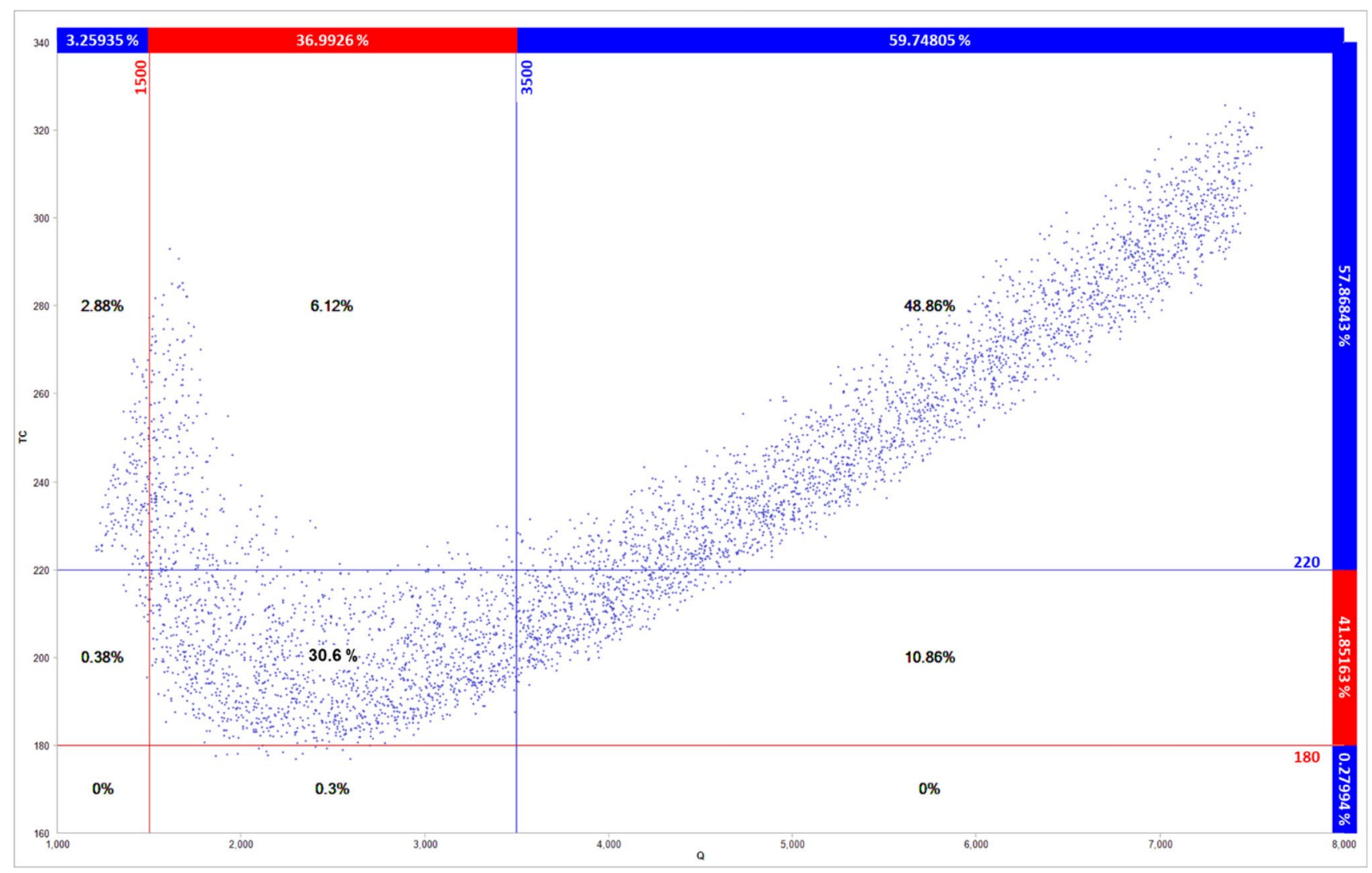

Fig. 3 Example of cost/quantity parametric decision-making process for the base scenario

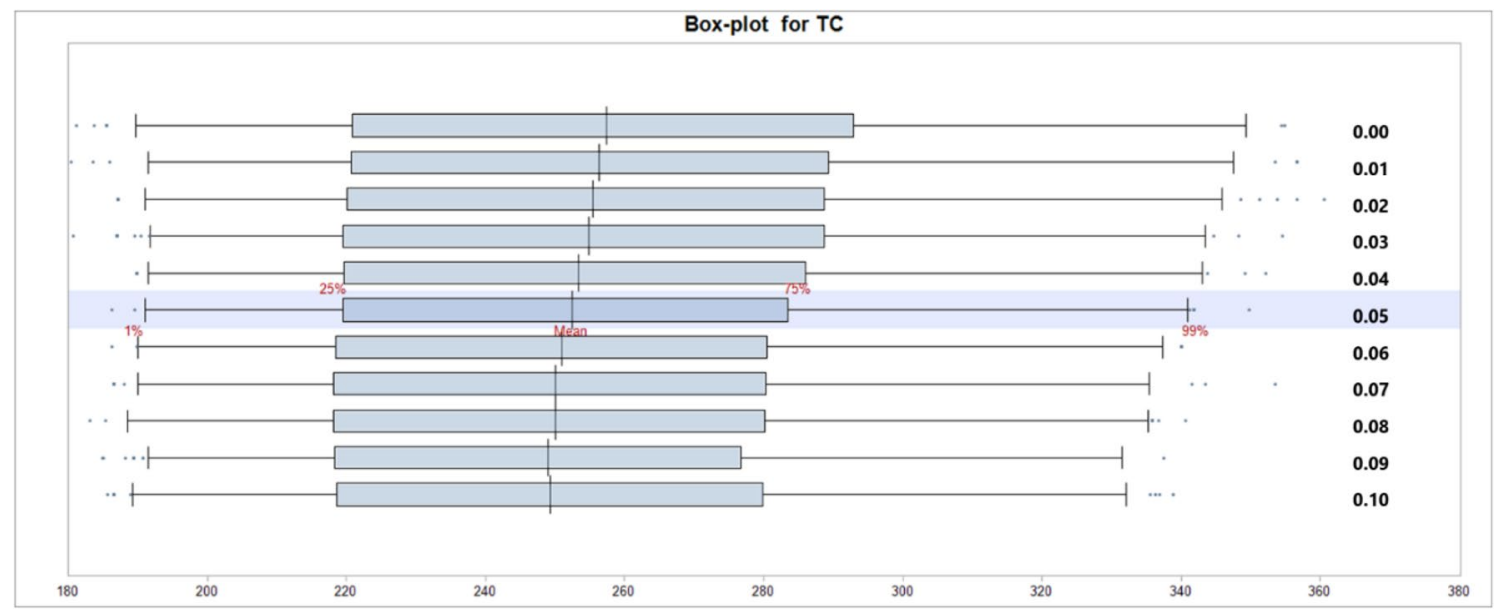

Fig. 4 Box-plot of total cost, with changing $\alpha$, highlighted item corresponds to $\alpha=0.05$

costs, as shown in Fig. 5. This increment is largely representative of the increment in the shortage costs $(\mathrm{ShC})$ and the lost sale costs (LsC), while negligible variations are experienced in the holding cost (HC). The sensitivity analysis is here stopped at $\theta=0.50$, representing a reasonable boundary condition for deterioration rate in line with previous research which usually reports a value of $\theta$ never exceeding 0.3 [9, $10,22]$. 


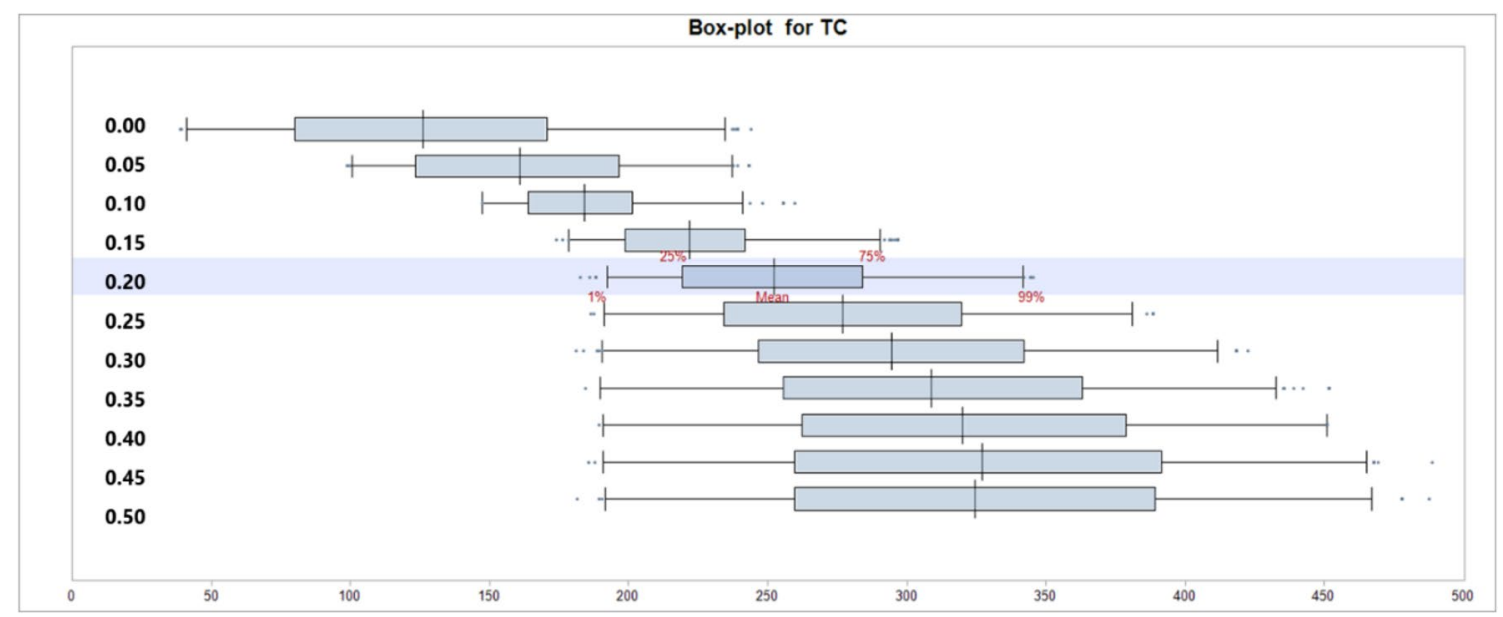

Fig. 5 Box-plot of total cost, with changing $\theta$, highlighted item corresponds to $\theta=0.20$

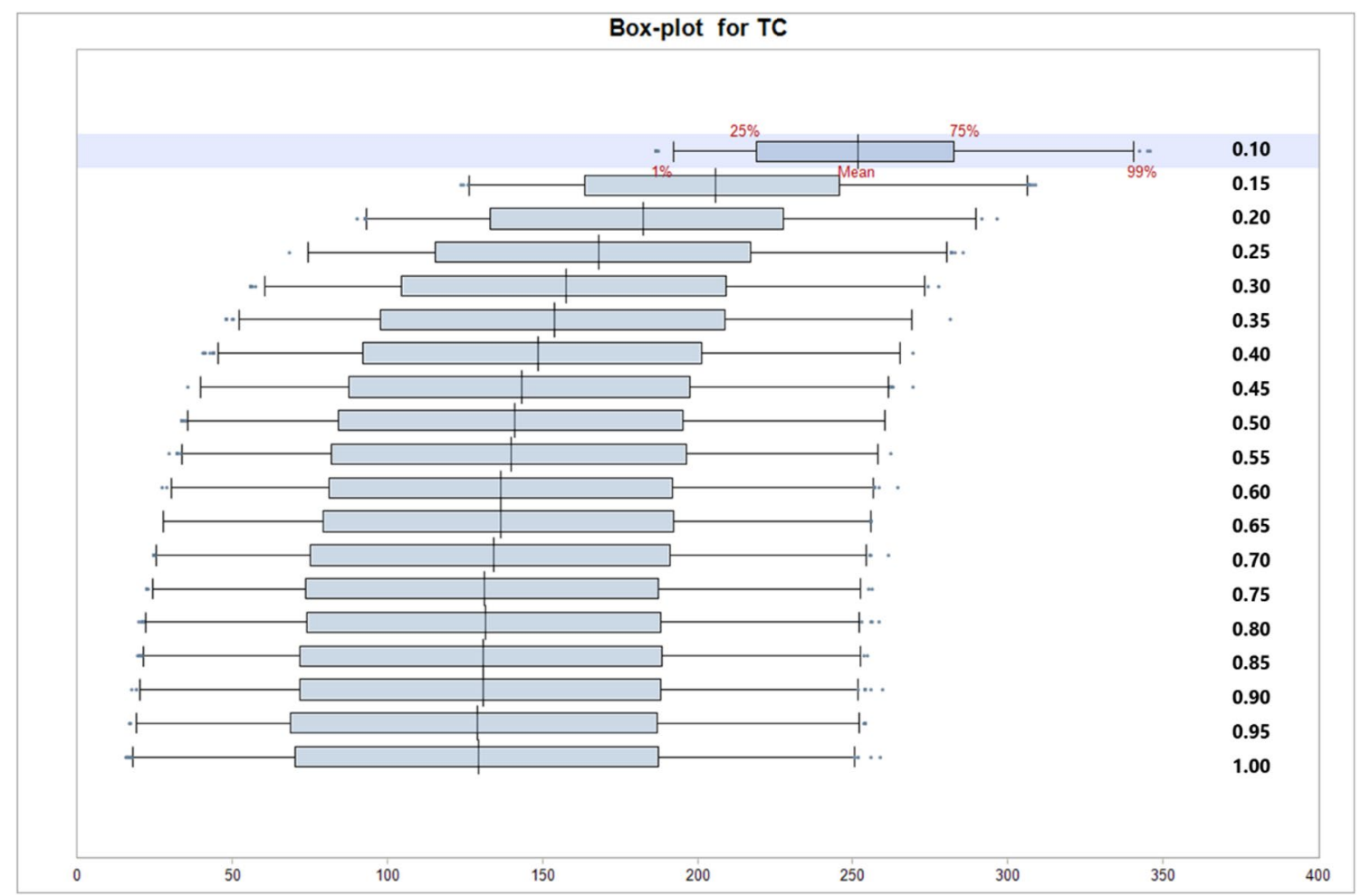

Fig. 6 Box-plot of total cost, with changing $\varphi$, highlighted item corresponds to $\varphi=0.10$

\subsubsection{Backlogging parameter}

The backlogging parameter $\varphi$ shows a non-negligible effect on the total cost. In the range from 0.1 to 1 , the total cost presents a decrease up to $\varphi=0.70$. As expected, the tendency is largely due to the effect on the shortage costs (ShC) which progressively are affected by a reduced randomness, due to the increased acceptance of the backlogging (see Figs. 6, 7). Minor effects are observable in lost sale costs (LsC), while negligible effects are presented in the other components of the cost function.

\section{Conclusions}

Current competitiveness requires dedicated strategies to deal with the uncertainty of market in highly dynamic settings. The paper presents an EOQ model which integrates a variety 


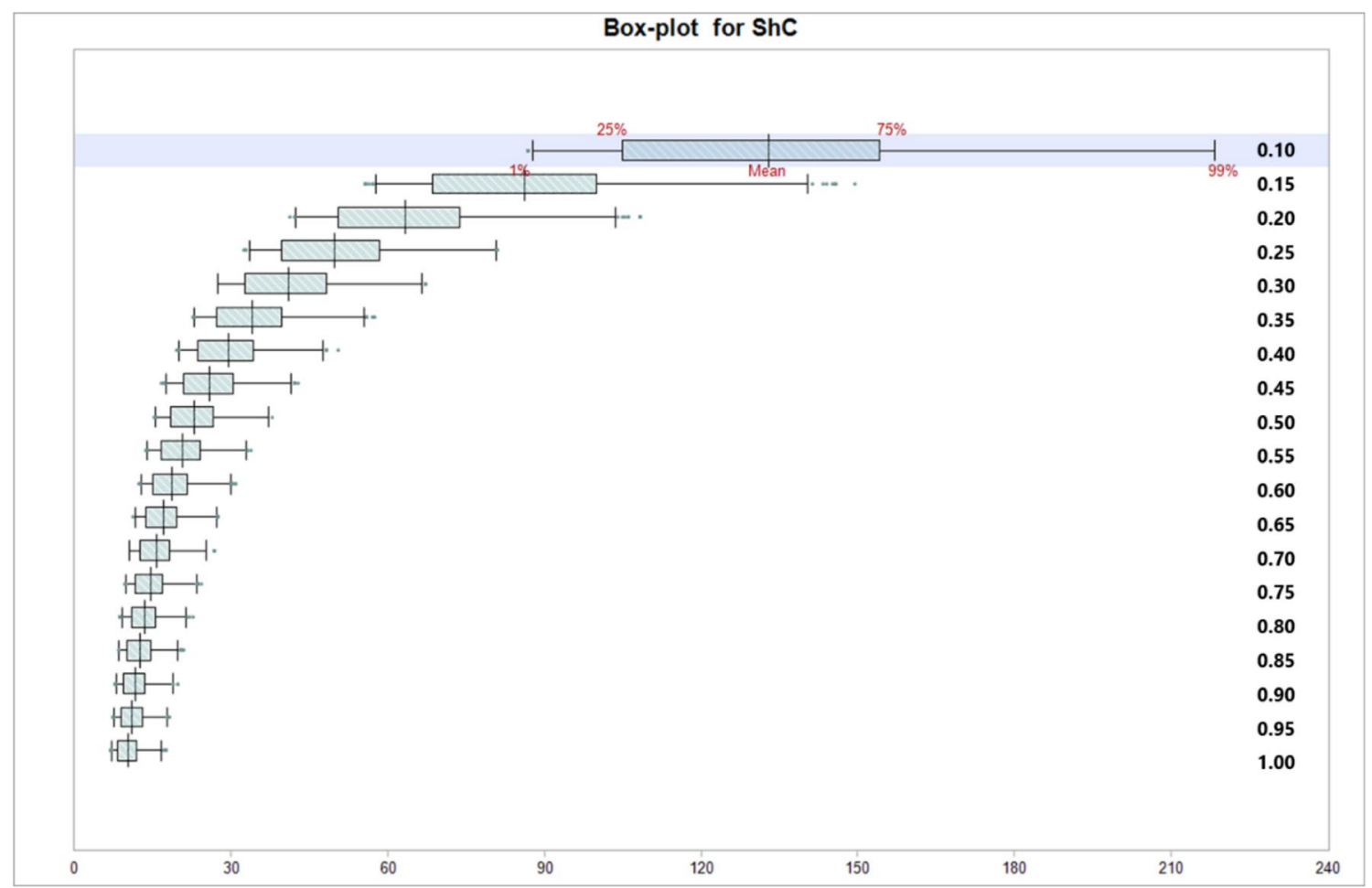

Fig. 7 Box-plot of shortage cost, with changing $\varphi$, highlighted item corresponds to $\varphi=0.10$

of products features to extend the credibility of the standard formulation also to cases affected by uncertainty, via a Monte Carlo simulation. The model allows the identification of advantageous quantity ranges for orders and the respective economic risk profile.

Furthermore, in more general terms, as proved by the cost sensitivity analysis, the model allows the isolation of the most significant variable dependencies (i.e. backlogging parameter, deterioration coefficient), supporting a parametric EOQ assessment.

Future research directions may include additional models of the deterioration process, i.e. other probability distribution functions suitable to represent the behaviours of specific products over time. Additionally, the framework could be enhanced to encompass other operations management aspects, (e.g.) permissible delay in payments, quantity discounts flexible re-ordering intervals. Considering the positive results obtained via the proposed Monte Carlo simulation in combination with the provided analytical framework, this research confirms the usefulness of the proposed approach as decision-making support tools able to ensure an effective inventory management for critical products.

The proposed framework can be adopted for a large variety of deteriorating items, whose market presence can also be indirectly affected by the pandemic scenario itself. In this sense, a proper setting of the input, as well as the decisional, variables allows a flexible optimization process. The framework remains also extensible to post-pandemic scenarios for traditional deteriorating products (e.g. milk, fruits, vegetables, among others), whose uncertainty is expected to be limited in (e.g.) the demand variability over time. In these cases, the decisional variables may also be adjusted to reflect proper risk appetite of the decision-makers or even be iteratively defined to run what-if scenarios.

Funding Open access funding provided by Università degli Studi di Roma La Sapienza within the CRUI-CARE Agreement.

Open Access This article is licensed under a Creative Commons Attribution 4.0 International License, which permits use, sharing, adaptation, distribution and reproduction in any medium or format, as long as you give appropriate credit to the original author(s) and the source, provide a link to the Creative Commons licence, and indicate if changes were made. The images or other third party material in this article are included in the article's Creative Commons licence, unless indicated otherwise in a credit line to the material. If material is not included in the article's Creative Commons licence and your intended use is not permitted by statutory regulation or exceeds the permitted use, you will need to obtain permission directly from the copyright holder. To view a copy of this licence, visit http://creativecommons.org/licenses/by/4.0/. 


\section{Appendix}

$$
\begin{aligned}
& H C_{1}=\int_{0}^{t_{1}} H(t) I_{1}(t) d t=\int_{0}^{t_{1}}(g+h t)\left(I_{0}-\left(a t+\frac{b}{2} t^{2}+\frac{c}{3} t^{3}\right)\right) \\
& d t==I_{0} t_{1}\left(g+\frac{h}{2} t_{1}^{2}\right)-\frac{t_{1}^{2}}{120}\left[10 g\left(6 a-2 b t_{1}-c t_{1}^{2}\right)-h t_{1}\left(40 a+15 b t_{1}-8 c t_{1}^{2}\right]\right. \\
& H C_{2}=\int_{t_{1}}^{\mu} H(t) I_{1^{\prime}}(t) d t=\int_{t_{1}}^{\mu}(g+h t)\left(I_{0}-\left(a t+\frac{b}{2} t^{2}+\frac{c}{3} t^{3}\right)-\alpha Q\right) \\
& d t==I_{0} \mu\left(g+\frac{h}{2} \mu\right)+g \mu^{2}\left(-\frac{a}{2}-\frac{b}{6} \mu-\frac{c}{12} \mu^{2}-\frac{\alpha Q}{\mu}\right)+h \mu^{2}\left(-\frac{a}{3} \mu-\frac{b}{8} \mu^{2}-\frac{c}{15} \mu^{3}-\frac{\alpha Q}{2}\right) \\
& +I_{0} t_{1}\left(-g-\frac{h}{2} t_{1}\right)+g t_{1}^{2}\left(\frac{a}{2}+\frac{b}{6} t_{1}+\frac{c}{12} t_{1}^{2}+\frac{\alpha Q}{t_{1}}\right)+h t_{1}^{2}\left(\frac{a}{3} t_{1}+\frac{b}{8} t_{1}^{2}+\frac{c}{15} t_{1}^{3}+\frac{\alpha Q}{2}\right) \\
& H C_{3}=\int_{\mu}^{t_{2}} H(t) I_{2}(t) d t=\int_{\mu}^{t_{2}}(g+h t)\left(\frac{1}{\theta}\left\{\left[\left(a+b t_{2}+c t_{2}^{2}\right)-\left(\frac{b+2 c t_{2}}{\theta}\right)+\frac{2 c}{\theta^{2}}\right] e^{\theta\left(t_{2}-t\right)}-\left[\left(a+b t+c t^{2}\right)-\left(\frac{b+2 c t}{\theta}\right)+\frac{2 c}{\theta^{2}}\right]\right\}\right) d t \\
& ==\frac{1}{\theta}\left[-\frac{t_{2}^{2}[\theta(a h \theta+b g \theta-b h)+2 c(h-g \theta)]}{2 \theta^{2}}-\frac{e^{\theta\left(t_{2}-t_{2}\right)}\left(g \theta+h t_{2} \theta+h\right)\left[\theta\left(a \theta+b\left(t_{2} \theta-1\right)\right)+c\left(t_{2}^{2} \theta^{2}-2 t_{2} \theta+2\right)\right]}{\theta^{4}}\right. \\
& \left.-\frac{g t_{2}[\theta(a \theta-b)+2 c]}{\theta^{2}}-\frac{t_{2}^{3}(b h \theta+c g \theta-2 c h)}{3 \theta}-\frac{1}{4} c h t_{2}^{4}\right]-\frac{1}{\theta}\left[-\frac{\mu^{2}[\theta(a h \theta+b g \theta-b h)+2 c(h-g \theta)]}{2 \theta^{2}}\right. \\
& \left.-\frac{e^{\theta\left(t_{2}-\mu\right)}(g \theta+h \mu \theta+h)\left[\theta\left(a \theta+b\left(t_{2} \theta-1\right)\right)+c\left(t_{2}^{2} \theta^{2}-2 t_{2} \theta+2\right)\right]}{\theta^{4}}-\frac{g \mu[\theta(a \theta-b)+2 c]}{\theta^{2}}-\frac{\mu^{3}(b h \theta+c g \theta-2 c h)}{3 \theta}-\frac{1}{4} \operatorname{ch} \mu^{4}\right]
\end{aligned}
$$

\section{References}

1. Osteryoung JS, Nosari E, McCarty DE, Reinhart WJ (1986) Use of the EOQ model for inventory analysis. Prod Invent Manag 27:39-46. https://doi.org/10.5555/15262.15268

2. Salameh MK, Jaber MY (2000) Economic production quantity model for items with imperfect quality. Int J Prod Econ 64:59-64. https://doi.org/10.1016/S0925-5273(99)00044-4

3. Moussawi-Haidar L, Salameh M, Nasr W (2014) Effect of deterioration on the instantaneous replenishment model with imperfect quality items. Appl Math Model 38:5956-5966. https://doi. org/10.1016/j.apm.2014.05.003

4. Tripathi RP, Uniyal AK (2015) Economic order quantity model for deteriorating items with time-dependent demand rate under time varying shortages. Int J Math Oper Res 7:706-719. https:// doi.org/10.1504/IJMOR.2015.072278

5. Karthikeyan K, Santhi G (2015) An inventory model for constant deteriorating items with cubic demand and salvage value. Int $\mathrm{J}$ Appl Eng Res 10:3723-3728

6. Khurana D, Chaudhary RR (2016) Optimal pricing and ordering policy for deteriorating items with price and stock dependent demand and partial backlogging. Uncertain Supply Chain Manag 4:307-318. https://doi.org/10.5267/j.uscm.2016.3.004

7. Mahapatra GS, Adak S, Mandal TK, Pal S (2017) Inventory model for deteriorating items with time and reliability dependent demand and partial backorder. Int J Oper Res 29:344-359. https ://doi.org/10.1504/IJOR.2017.084340
8. Kumar P (2019) Inventory optimization model for quadratic increasing holding cost and linearly increasing deterministic demand. Int J Recent Technol Eng 7:1999-2004

9. Tripathi RP (2019) Innovation of economic order quantity (EOQ) model for deteriorating items with time-linked quadratic demand under non-decreasing shortages. Int J Appl Comput Math 5:1-13. https://doi.org/10.1007/s40819-019-0708-x

10. Shaikh AA, Khan MAA, Panda GC, Konstantaras I (2019) Price discount facility in an EOQ model for deteriorating items with stock-dependent demand and partial backlogging. Int Trans Oper Res 26:1365-1395. https://doi.org/10.1111/itor.12632

11. Ahmad B, Benkherouf L (2018) Economic-order-type inventory models for non-instantaneous deteriorating items and backlogging. RAIRO Oper Res 52:895-901. https://doi.org/10.1051/ ro/2018010

12. Tat R, Taleizadeh AA, Esmaeili M (2015) Developing economic order quantity model for non-instantaneous deteriorating items in vendor-managed inventory (VMI) system. Int J Syst Sci 46:12571268. https://doi.org/10.1080/00207721.2013.815827

13. Palanivel M, Uthayakumar R (2015) Finite horizon EOQ model for non-instantaneous deteriorating items with price and advertisement dependent demand and partial backlogging under inflation. Int J Syst Sci 46:1762-1773. https://doi.org/10.1080/00207 721.2013.835001

14. Mishra PJ, Singh T, Pattanayak H (2016) An EOQ inventory model for deteriorating items with linear demand, salvage value and partial backlogging. Int J Appl Eng Res 11:6479-6484

15. Singh T, Mishra PJ, Pattanayak H (2017) An optimal policy for deteriorating items with time-proportional deterioration rate and 
constant and time-dependent linear demand rate. J Ind Eng Int 13:455-463. https://doi.org/10.1007/s40092-017-0198-6

16. Rajoria YK, Saini S, Singh SR (2015) EOQ model for decaying items with power demand, partial backlogging and inflation. Int J Appl Eng Res 10:22861-22874

17. Sharma S, Singh S, Singh SR (2018) An inventory model for deteriorating items with expiry date and time varying holding cost. Int J Procure Manag 11:650-666. https://doi.org/10.1504/ IJPM.2018.094357

18. Pervin M, Roy SK, Weber G-W (2018) Analysis of inventory control model with shortage under time-dependent demand and timevarying holding cost including stochastic deterioration. Ann Oper Res 260:437-460. https://doi.org/10.1007/s10479-016-2355-5

19. Sanni SS, Chukwu WIE (2016) An inventory model with three-parameter weibull deterioration, quadratic demand rate and shortages. Am J Math Manag Sci 35:159-170. https://doi. org/10.1080/01966324.2015.1126697

20. Singh T, Mishra PJ, Pattanayak H (2018) An EOQ inventory model for deteriorating items with time-dependent deterioration rate, ramp-type demand rate and shortages. Int J Math Oper Res 12:423-437. https://doi.org/10.1504/IJMOR.2018.092103

21. Palanivel M, Uthayakumar R (2016) Finite horizon EOQ model for non-instantaneous deteriorating items with probabilistic deterioration and partial backlogging under inflation. Int J Math Oper Res 8:449-476. https://doi.org/10.1504/IJMOR.2016.07678 4

22. Mahata P, Mahata GC, De SK (2020) An economic order quantity model under two-level partial trade credit for time varying deteriorating items. Int J Syst Sci Oper Logist 7:1-17. https://doi. org/10.1080/23302674.2018.1473526

23. Jaggi CK, Goel SK, Mittal M (2011) Economic order quantity model for deteriorating items with imperfect quality and permissible delay on payment. Int J Ind Eng Comput 2:237-248. https:// doi.org/10.5267/j.ijiec.2010.07.003

24. Di Gravio G, Mancini M, Patriarca R, Costantino F (2015) Overall safety performance of air traffic management system: forecasting and monitoring. Saf Sci. https://doi.org/10.1016/j. ssci.2014.10.003

Publisher's Note Springer Nature remains neutral with regard to jurisdictional claims in published maps and institutional affiliations. 